\title{
Editorial: Changes in the editorial team
}

I will hand on the role of Editor of Ageing $\mathcal{E}$ Society at the end of the year. My last eight-and-a-half years in the role have seen immense changes in the journal and in gerontology research and scholarship, and have been richly rewarding, but I will expound on such matters elsewhere. This editorial is exclusively to provide information about the editorial vacancies that are now advertised.

The Editorial Board and Cambridge University Press are very keen to support the continued development of the journal and have agreed that, as well as appointing an Editor-in-Chief, two further Associated Editors will be recruited to work alongside Mima Cattan and Jim Ogg. There are two reasons for the expansion of the editorial team: the steady increase in the editorial workload, and the Board's keen wish to create posts that are consistent with the heavy time demands on academics in contemporary universities, not least the intense pressure to publish. We wish to dispel any notion that being an Editor of Ageing $\mathcal{E}$ Society is intolerably time consuming.

Broad estimates of the workload for each Editor under the new arrangements can be made. During 2009, 217 new papers were submitted, 25 per cent more than in 2008. I will be surprised if that rate of growth continues, but one can readily expect 280 submissions during 20II. As there are always a minority of manifestly unsuitable papers, which Miles Lambert and the Editor-in-Chief quickly identify, around 250 will proceed to review. If the workload is distributed evenly among five editors, each will have to carry out the initial appraisal, nominate reviewers, and later compose decision letters for $5^{\circ}$ papers - one during each week of the year. The other substantial elements of the editors' work are evaluating the revised papers that are re-submitted, and preparing finally accepted papers for the press. In 2009, the journal published $5^{6}$ papers. Already agreed page-length increases mean that one can expect the number to grow to around 65 by 20I. Each Editor will therefore shepherd through to publication around I3 papers during $201 \mathrm{I}$.

The Board welcomes applications from social gerontologists of any discipline - indeed all those working on issues connected with societal or individual ageing and the welfare and experiences of older people. We also invite applications from outside the United Kingdom, although an essential requirement is very good proficiency in the English language. Nor 
should it be thought that only those with university posts can apply. Researchers and analysts affiliated to policy and advocacy organisations would add new dimensions to the experience and insights of the editorial team, and so be welcome, but applicants must have Internet access and computer support.

Notice of the vacancies and details of the application procedure are on the journal's pages of the CUP website at http://journals.cambridge/aso. Once the new team is appointed, they will recommend to the Editorial Board the detailed allocation of roles. Mima Cattan, Jim Ogg and I welcome informal inquiries about the editorial roles. If you wish to contact us, please do so initially by email, and include a telephone number (a.warnes@sheffield.ac.uk; mima.cattan@northumbria.ac.uk; jim.ogg@ cnav.fr).

Working on Ageing \& Society is immensely rewarding, and the new, larger team will be an exceptionally stimulating group. If you had thought that being an editor is not for you, think again.

TONY WARNES for the Editorial Board 